\title{
Pulmonary Rehabilitation and Physiotherapy Management of Respiratory Conditions in Patient with COVID-19: Narrative Review
}

\author{
${ }^{*}$ Soleimanifar. $\mathrm{M}^{1}$ \\ Hazrati. $E^{2}$ \\ 1- ( ${ }^{*}$ Corresponding Author) \\ PhD of Physical Therapy, \\ Assistant Professor, Lifestyle \& \\ Health Management Research \\ Group, ACECR, Tehran.Iran. \\ Email: \\ manijeh.soleimanifar@yahoo.com \\ 2- Assistant Professor, Department \\ of Anesthesia and Intensive \\ Care, Faculty of Medicine, Aja \\ University of Medical Sciences, \\ Tehran, Iran.
}

\begin{abstract}
Introduction: COVID-19 is a disease caused by a novel type of coronavirus which primarily affects the respiratory system, induces mild pulmonary symptoms (e.g cough and dyspnea), is easily recovered and causes pneumonia in severe cases. It gets to admit the patientsin the intensive care unit. Physiotherapy and pulmonary rehabilitation play an important role in improving respiratory function andclearance of airway secretions by chest physiotherapy and breathing exercises techniques.

Objective: The present study aimed to summarize applied information and make patients and caregivers aware of effective pulmonary physiotherapy methods to reduce symptoms of pulmonary involvement, improve respiratory function and reduce the length of stay in intensive care units.

Results: In this review, PubMed, Google Scholar, Science direct and SID databases were used to search for articles with keywords suhc as Breathing exercises,/Chest therapy “AND” pulmonary/,Respiratory disease/,COVID-19 OR Coronavirus.

Discussion and Conclusion: Based on the guideline on the treatment of COVID-19 patients released for physiotherapists in March 2020 , cardiopulmonary physiotherapy focuses on the treatment and rehabilitation of patients with acute and chronic respiratory conditions, and improves the physical fitness of those who had the disease. Thus, physiotherapy can play an effective role in respiratory and physical rehabilitation of patients with COVID 19.
\end{abstract}

Keywords: Breathing Exercises, Coronavirus, Chest Pulmonary, Disease, Therapy. 


\section{توانبخى ريوى و درمان فيزيوترابى عوارض تنفسى بيماران مبتلا به ويروس كوويد-19: مطالعه مرور نقلى

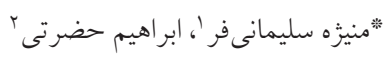

جكيده

مقدمه: COVID-19 بيمارى است كه با يك نوع جديد ويروس كرونا ايجاد شده است و به طور اوليه بر سيستم تنفسى

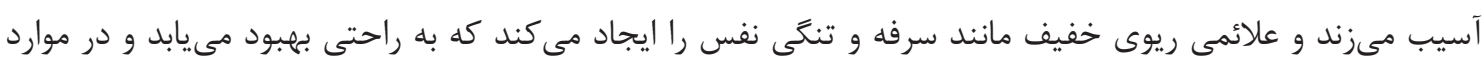

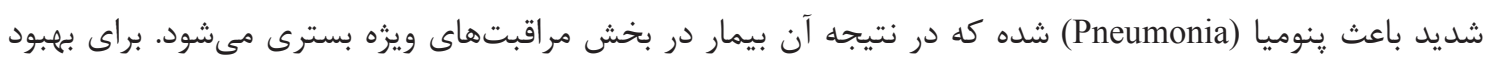

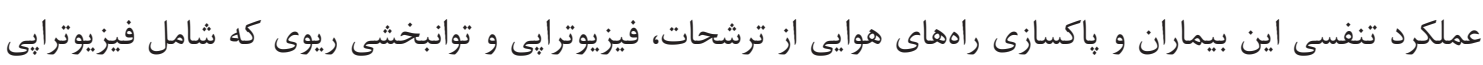

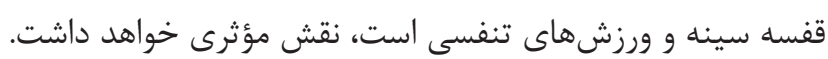

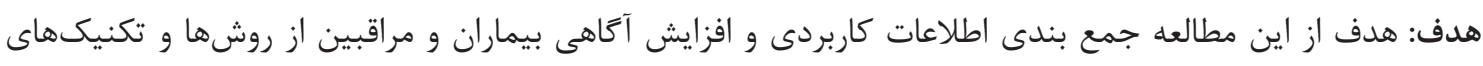

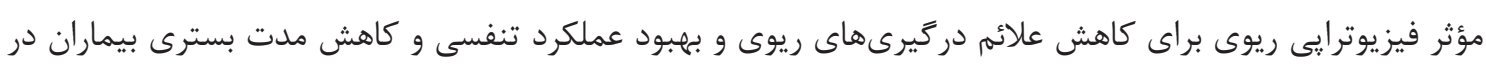
بخش مراقبتهاى ويزه است.

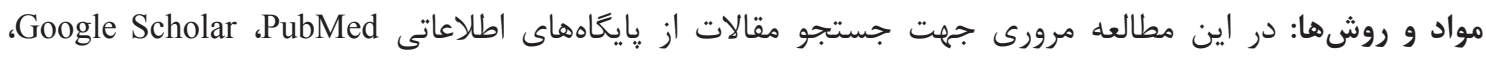

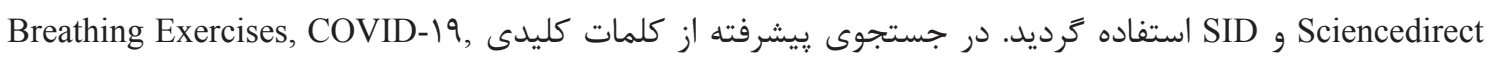
Respiratory Disease, Pulmonary, Chest therapy

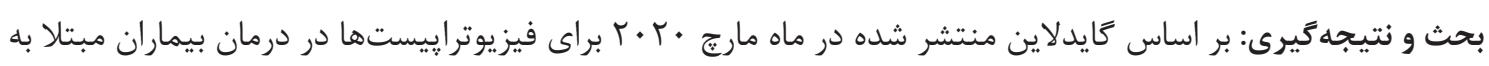

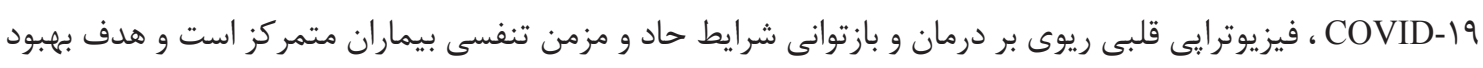

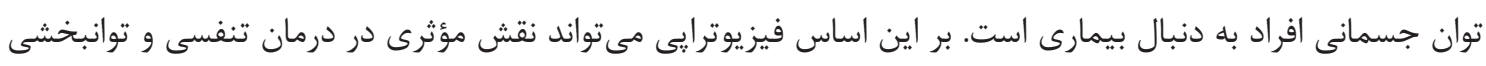

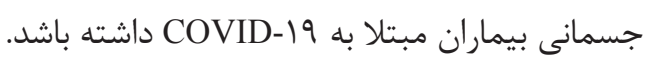

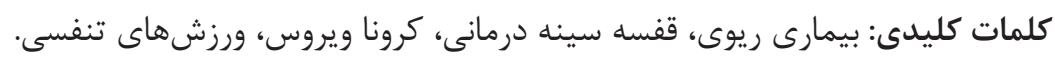

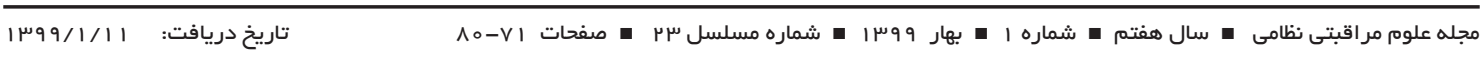

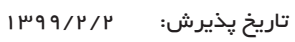

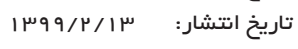

معمولاً كرونا ويروسها ابتدا در مخاط مزَكدار تنفسى در ناحيه

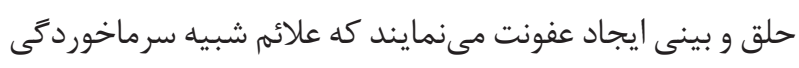

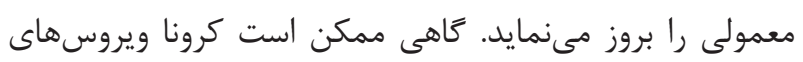

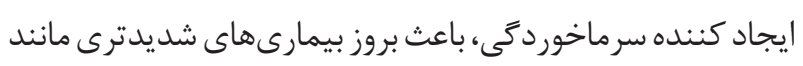

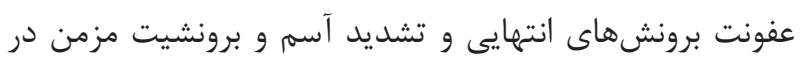
بالغين و حتى عفونت ريه (ينومونى) در بالغين، سالمندان و افراد

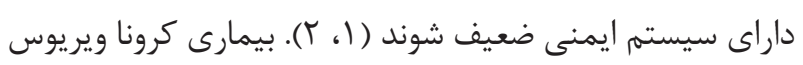

كرونا ويروسها (Coronaviruses) خانواده بزركى از ويروسها هستند. از اين مجموعه تاكنون هفت كَونه منتقل شده برونه

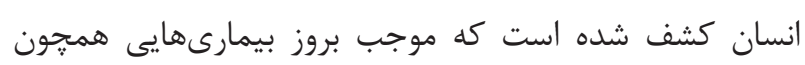
سرماخوردىى در انسان مى گردند. كرونا ويروس ها اغلب به دستَّاه تنفسى حمله مى كنند و گاهى علائم خود را در روده و معده افراد نمايان مى كنند (1) 
در بخش مراقبت ويزه به دليل كوويد 19 داشته باشند.

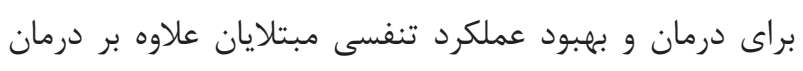

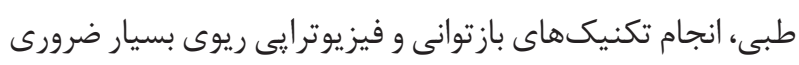

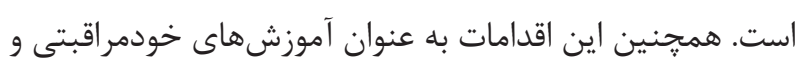
ورزشهاى تنفسى براى بيماران قرنطينه در منزل توصيه مىشود. توانبخشى ريوى تكنيكهاى متعدد و مختلفى دارد كه از جمله آن ها مى توان به تمرينهاى تنفسى و فيزيوترايى قفسه سينه سينه اشاره

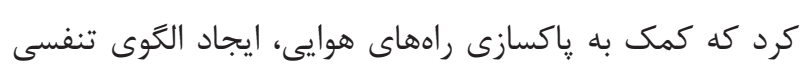

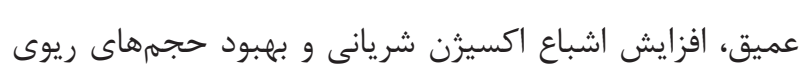

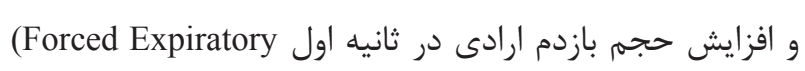
(Forced و ظرفيت حياتى اجبارى Volume in First Second) (V) Vital Capacity)

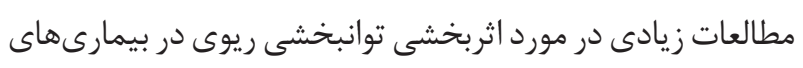

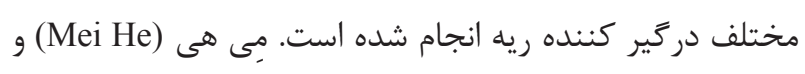

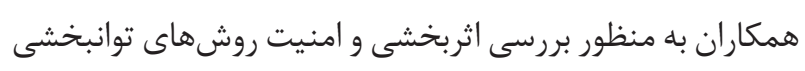
ريوى مطالعهاى بر روى ع9 بيمار مبتلا به انسداد مزمن ريوى باني دركيرى حاد انجام دادند. مداخلات توانبخشى از روز دوم بسترى دئي

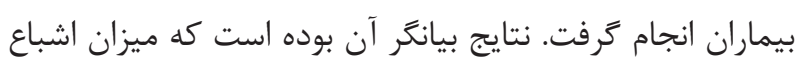

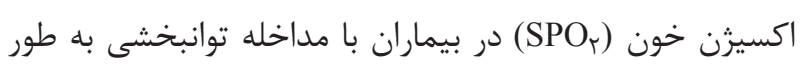

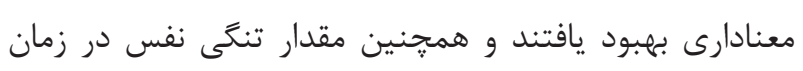
ورزش بر اساس مقياس بورى (Borg) در گروه مداخله به طور

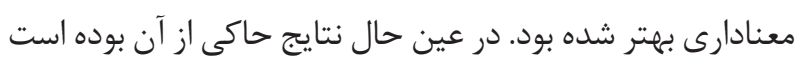
كه انجام تمرينات و مداخلات توانبخشى كاملاً ايمن بوده و هيج آسيب بالينى بر بيماران نداشته است (^).

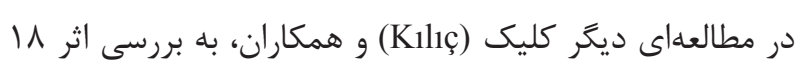
جلسه توانبخشى ريوى بر بيمارانى كه كانديد عمل ييوند ريه ديه

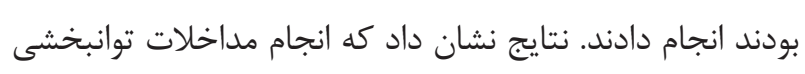

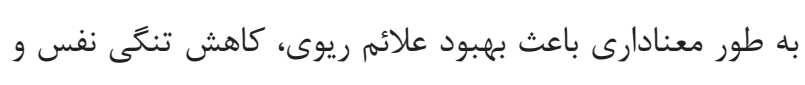
افزايش ظرفيت تنفسى بيماران شده است (9).

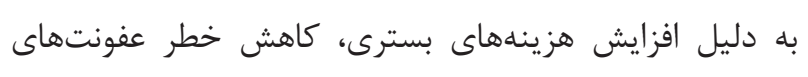

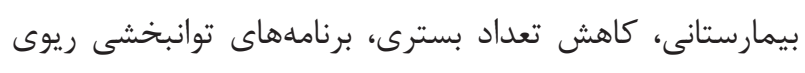

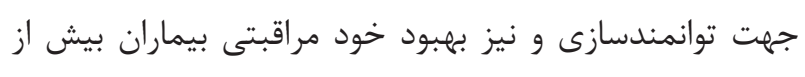

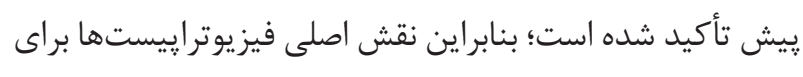

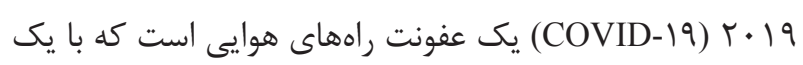

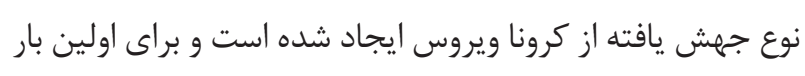

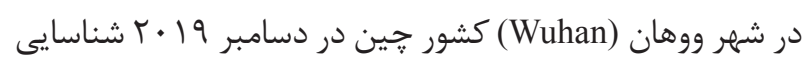

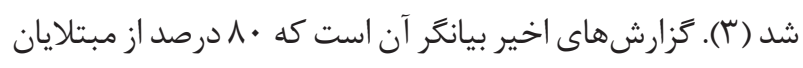

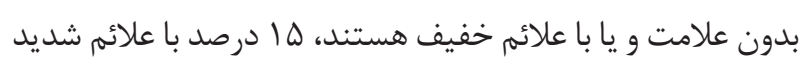

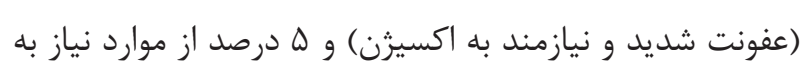
ونتيلاتور و تهويه مكانيكى دارند (Y).

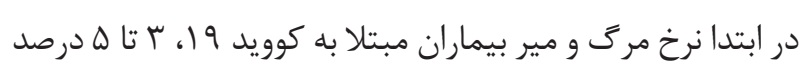

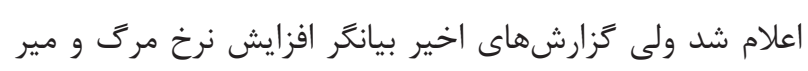

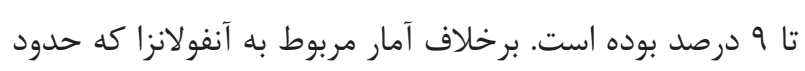

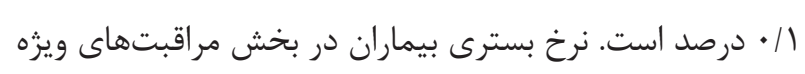

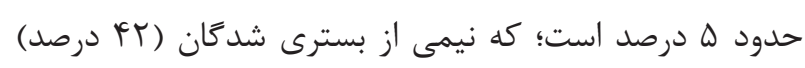

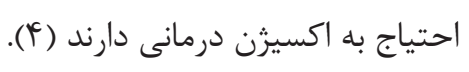

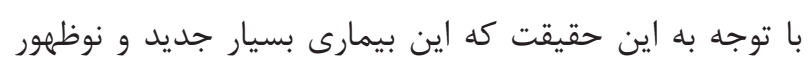

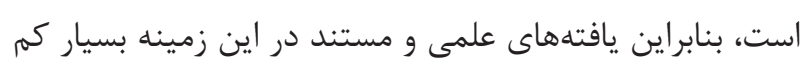
است. لذا، با نظر به عوارض ثانويهاى كه اين بيمارى بر سيستم

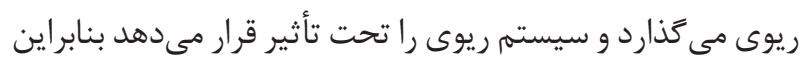

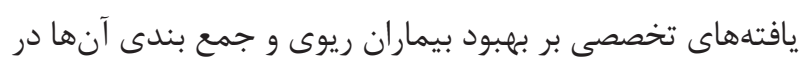

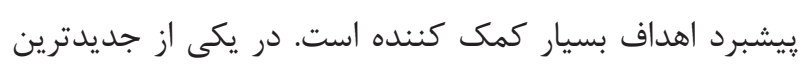

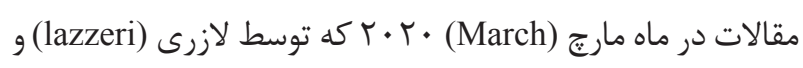

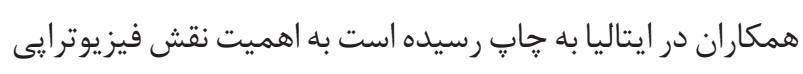
تنفسى و فيزيوترايى قفسه سينه در بيماران مبتلا به كوويد 19

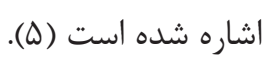

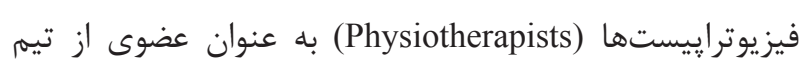
קند

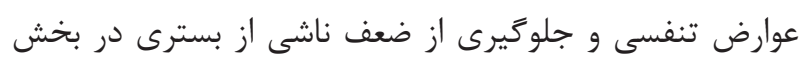

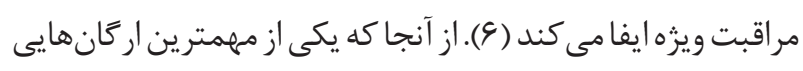

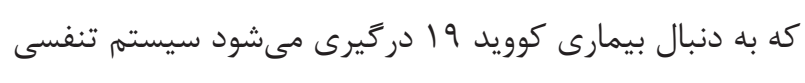

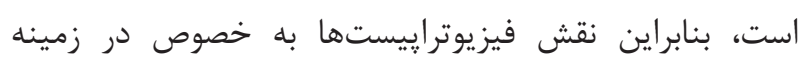

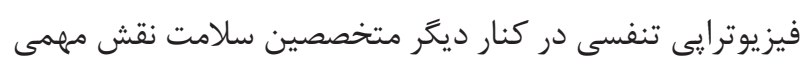

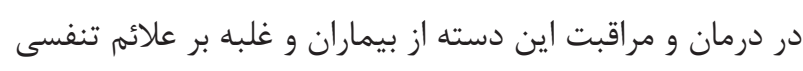

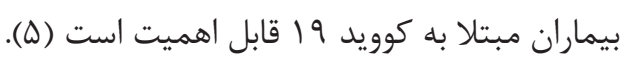

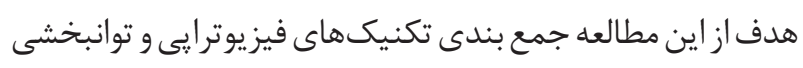

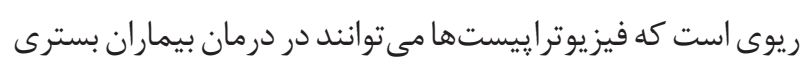


ترشحات راههاى تنفسى از جمله مخاط كمك مى كند و به اين

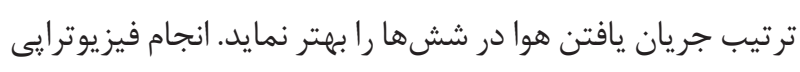

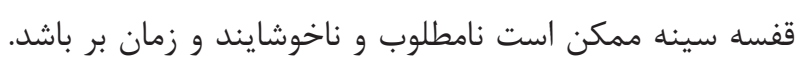

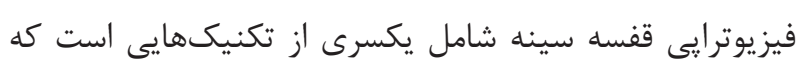
توسط فرد ديخر از جمله فيزيوتراييست تنفسى انجام مى فئود

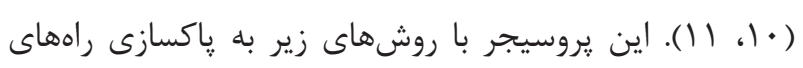

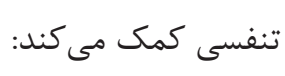

\section{ا. تخليه وضعيتى يا برونشى (Postural or bronchial drainage)}

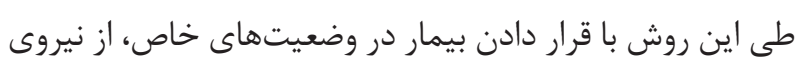

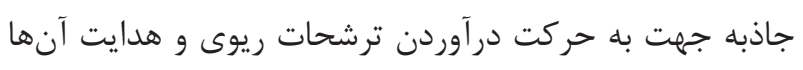
به سمت راههاى هوايى مركزى استفاده مىشود (شكل () (1) (I). زمان انجام وضعيت دهى بهتر است در اول صبح انجام شود تا

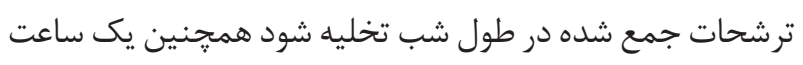

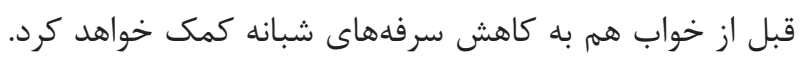

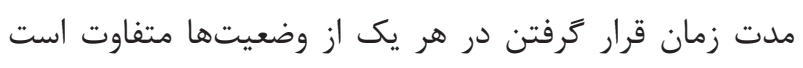

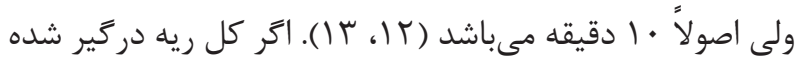

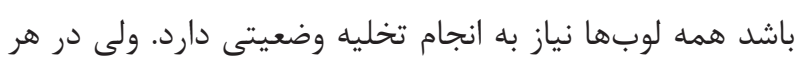

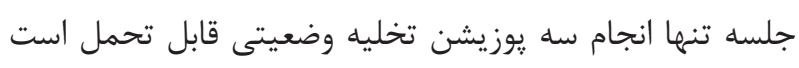

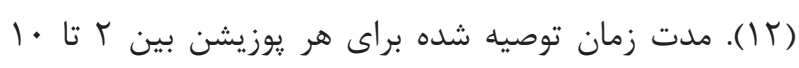

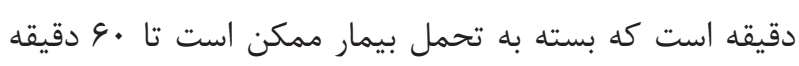

$$
\text { نيز ادامه يابد (ب ا) ). }
$$

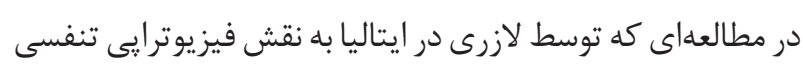
در بيماران COVID-19 منتشر شده است توصيه شده است كسانى لون

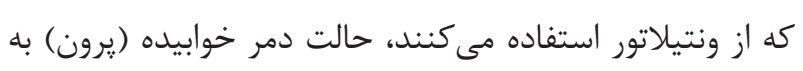

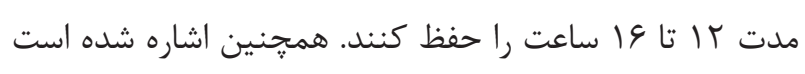

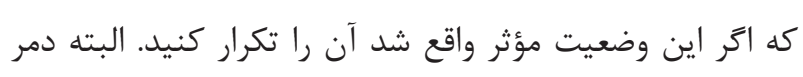
خوابيدن يكسرى عوارض از جمله زخمهاى فشارى، ادم صورت و ورئ

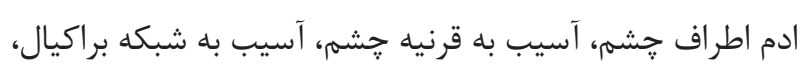
وضعيت نامناسب گوش، مشكل دسترسى به عروق و ثبات سوند

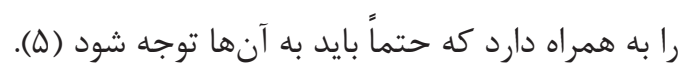

r. بر كاشن و ويبريشن (Percussion \& Vibration) يركاشن و ويبريشن در يوزيشنهاى تخليه وضعيتى با هدف ويرئن (Pن
بر ادامه و پِيخيرى آن در منزل بيش از پِيش آشكار مى گرددد

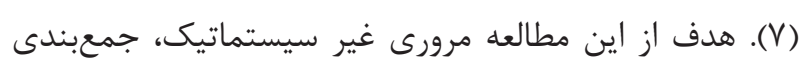

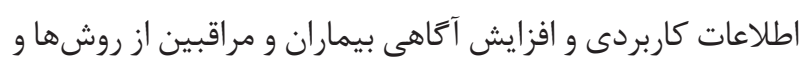
تكنيكهاى مؤثر فيزيوترايى ريوى براى كاهش علائم در كيرى هاى إنى

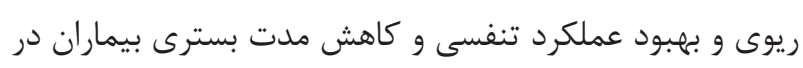
بخش مراقبتهاى ويزه به دليل عوارض ريوى كوويد 19 است.

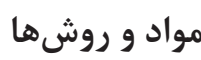

در اين مطالعه مرورى نقلى، جهت جستجو مقالات از پايخاههاى روشاى

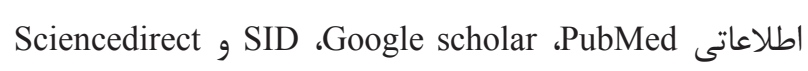
استفاده كرديد. در ابتدا براى دستيابى به اطلاعات جديد در مورد

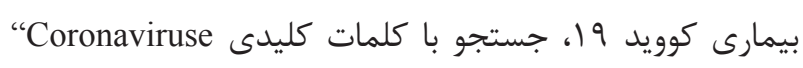
OR COVID-19" AND "Breathing exercises OR Chest انجام شد. ولى به دليل جديد بودن اين إيدمى و "Berapy”

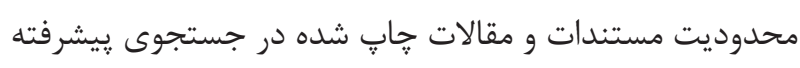
از كلمات كليدى "Breathing exercises OR Chest therapy" فND "pulmonary OR respiratory disease"

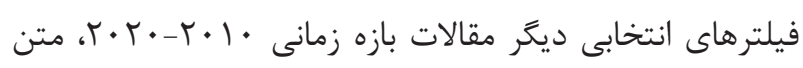

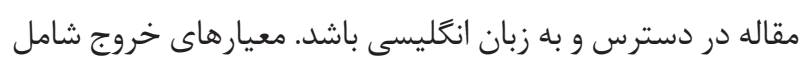

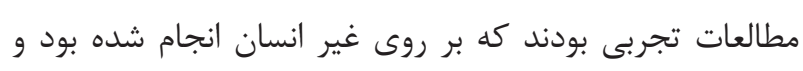

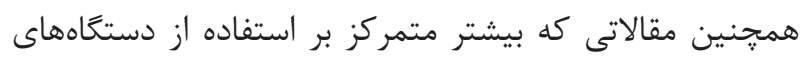
تهويه مصنوعى بودند. در جستجوى تكميلى از رفرنس هاى مقالات

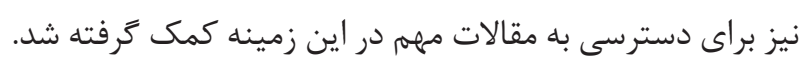

يافتهها

در ياسخ به سؤال اصلى يُوهش، نتايج مطالعات حاكى از آن بود

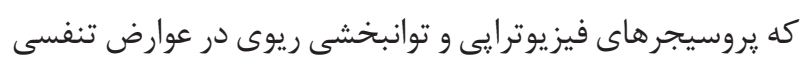

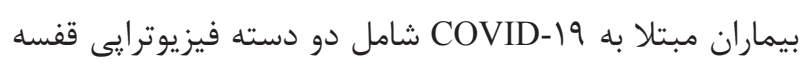

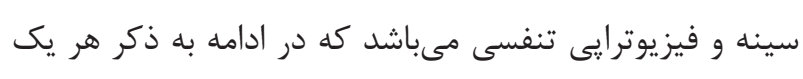

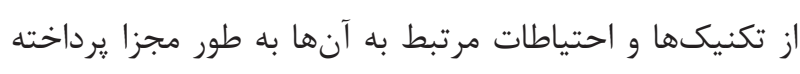
شده است.

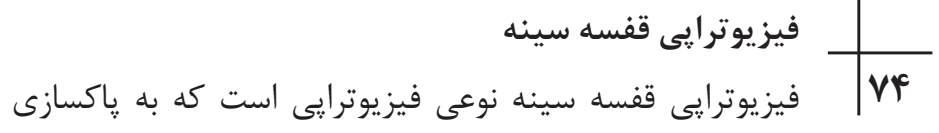




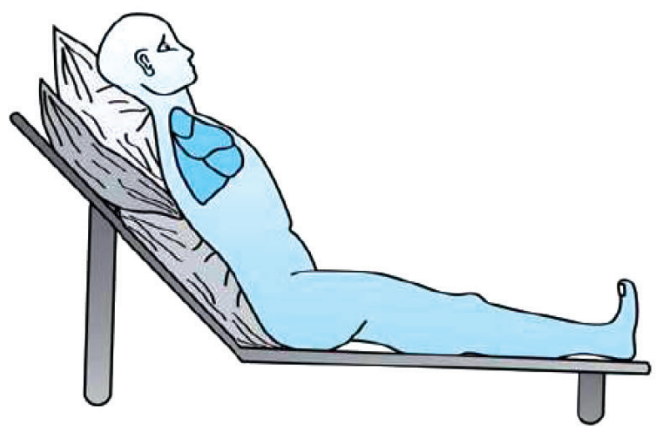

Apical segments of both upper lobes

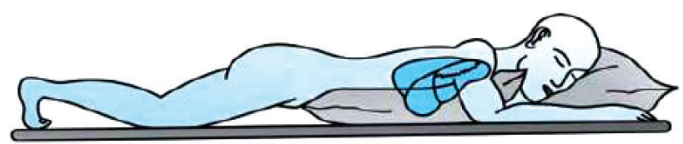

Posterior segment of right upper lobe

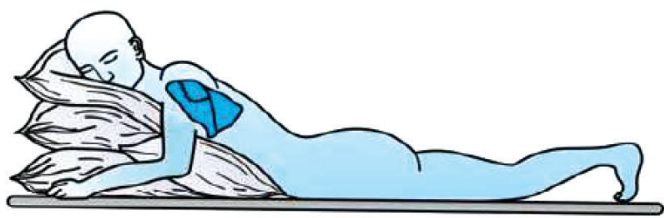

Posterior segment of the left upper lobe

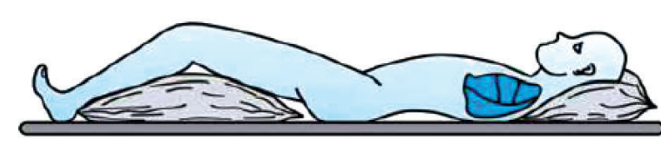

Anterior segments of both upper lobes

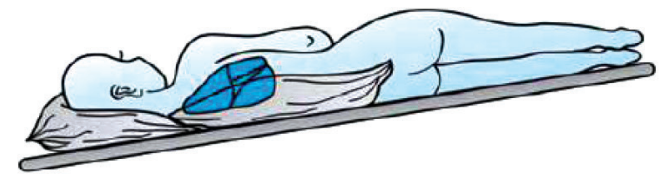

Lateral and medial segments of middle lobe

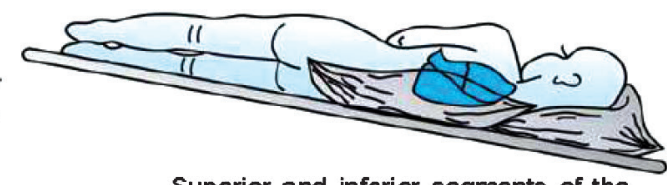

Superior and inferior segments of the lingula lobe

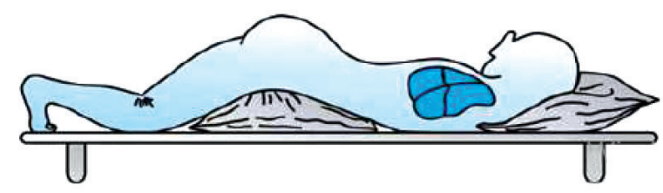

Apical segments of both lower lobes

$$
\text { شكل ا- يوزيشنهاى مختلف تخليه وضعيتى }
$$

سينه به سمت بالا ضربه وارد كرد. اين كار در هر دو سمت قفسه سينه تكرار مى گردد و بايد سعى شود ضربهها در تمامى

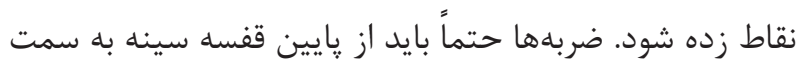
بالا زده شود. فر كانس ريشنهادى ير كاشن r تا V ضربه در هر

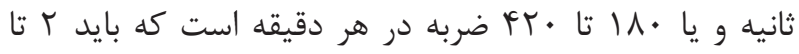
f دقيقه به صورت متوالى در هر سگمنت (Segment) از ريه

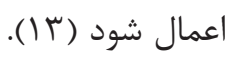
در روش ويبريشن يكسرى حركات ريز نوسانى توسط دستها
جداسازى ترشحات از ديواره راههاى هوايى انجام مىشود. ير كاشن به صورت انجام كف زدن ريتميك بر روى قفسه سينه، در حالى كه مج دست آزاد و دست در وضعيت فنجانى و گود قرار زرفته است و انرزى را به راههاى هوايى محيطى منتقل مى كند، انجام

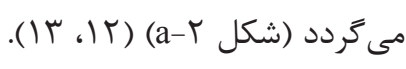
جهت انجام ير كاشن ابتدا بايد بيمار را حدود •r- •· دقيقه با آب ساده بخور داد. سيس بيمار را به صورت نيمه نشسته قرار داده و دست را به صورت كاسه در آورده و از سمت پايين قفسه

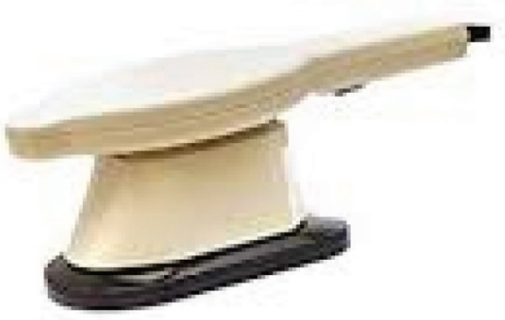

c

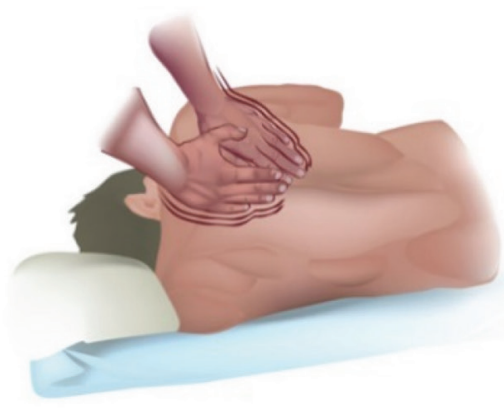

b

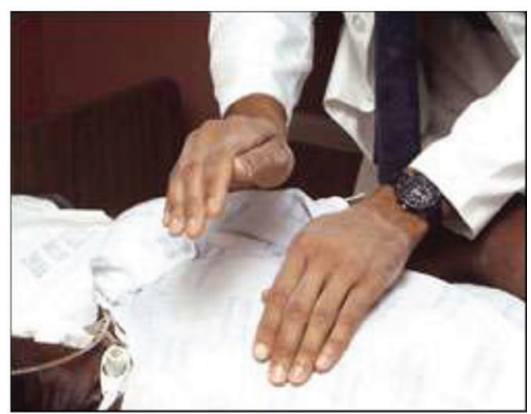

a شكل r- روش انجام تكنيكهاى تنفسى: a ) ير كاشن b) ويبريشن دستى c) دستخاه ويبراتور (ماسازور) جهت انجام ويبريشن 
دجار كلايس، بهبود اكسيزن رسانى، بهبود كميليانس ريوى و

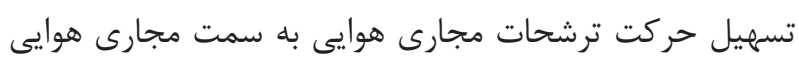

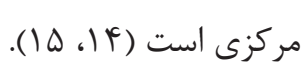

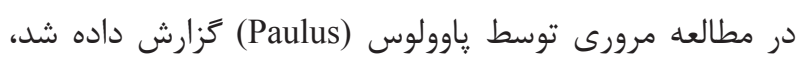

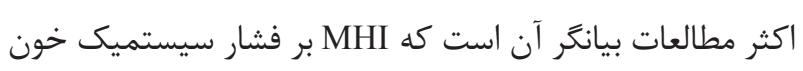

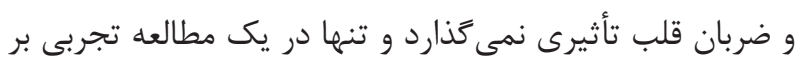

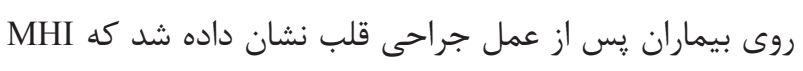

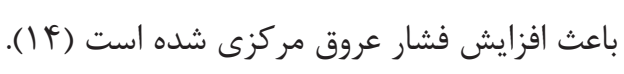

\section{فيزيوترايى تنفسى}

فيزيوترايى تنفسى به عنوان يك مداخله درمانى است كه شامل تنفس اصلاح الكَىى تنفسى، تقويت عضلات سيستم تنفسى، تخليه

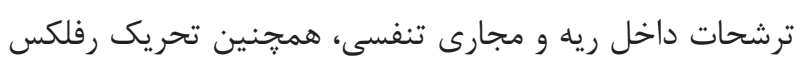

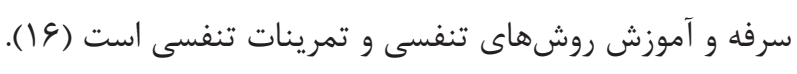

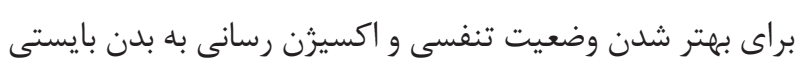
اين مداخله به روشهايى كه در زير توضيح داده مىشود، انجام

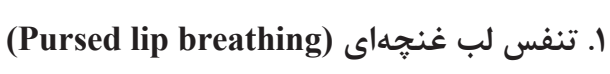
تنفس لب غنجهاى يك ورزش تنفسى ساده و راحت براى كاهش تُش علائم تنكى نفس است و باعث مي شود تنفس مؤثرتر و فر كانس بنس

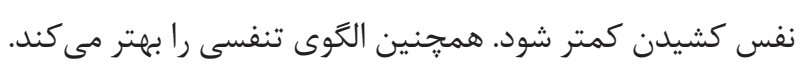
همجنين باعث مىشود راههاى هوايى در زمان طولانى ترى بـى باز

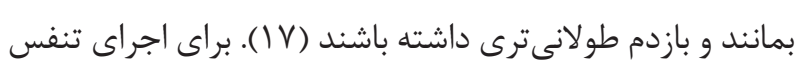
لب غنجهاى آموزش زير بايد داده شود: 1- در وضعيت راحت بنشينيد.
بر روى ديواره قفسه سينه، در زمان بازدم پس از انجام يك دم

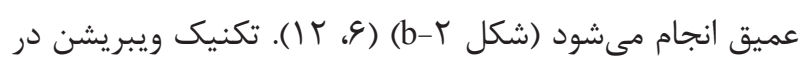

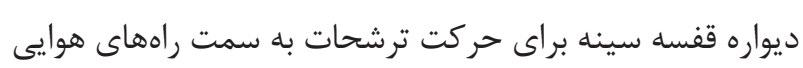

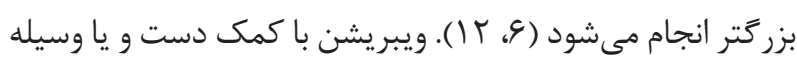

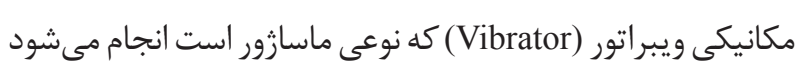
( شكل r انجام ير كاشن و ويبر يشن بايد با تنفس عميق و آرام انجام شود تااز

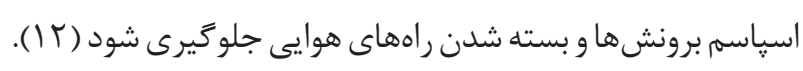
در حين اين عمل بيمار را بايد تشويق به سرفه كرد. سيس بيس بيمار

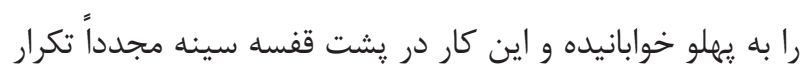

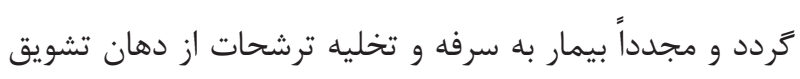

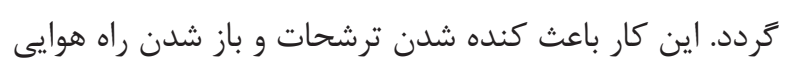

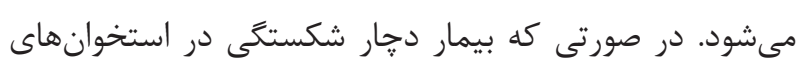

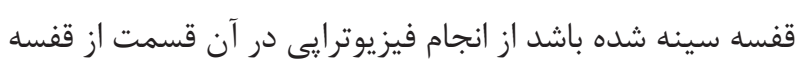
سينه بايستى اجتناب شود.

r. باد شدكى بيش از حد دستى - Manual hyperinflation)

MHI)

بادشدىى بيش از حد دستى (MHI) به عنوان روش فشردن كيسه هوايى شناخته شده است كه شامل يك دم كند و عميق از

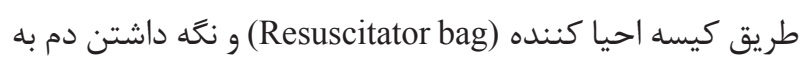

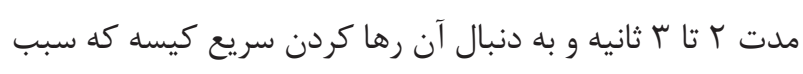

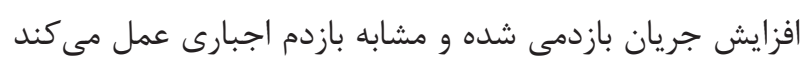

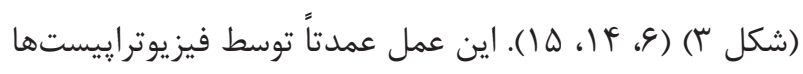

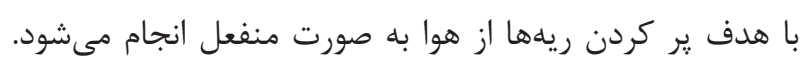

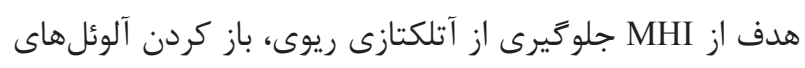

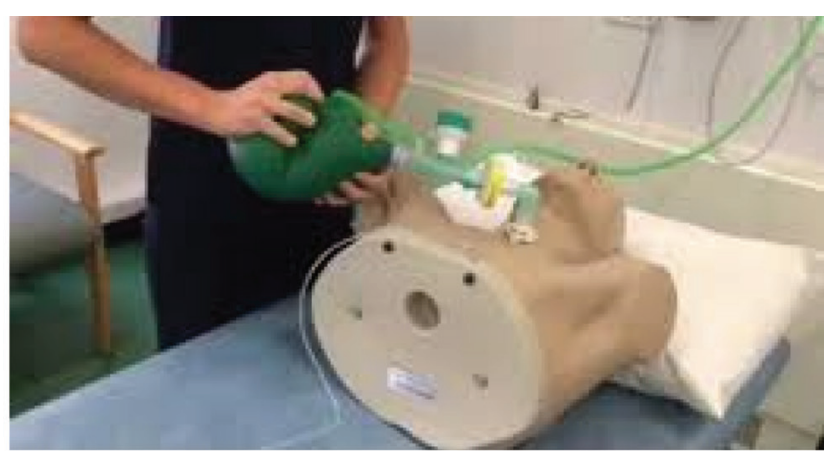

شكل r- باد شدكى بيش از حد دستى (Manual hyperinflation- MHI) 

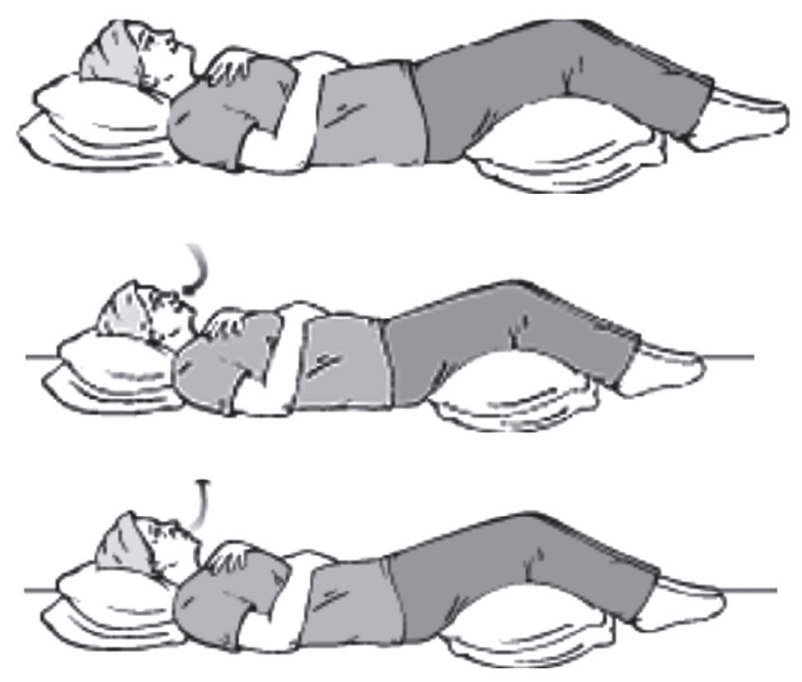

شكل ه - تنفس ديافراگماتيك

تأثير آنى تنفس ديافراگمى شامل افزايش حجم جارى Tidal) (volume)

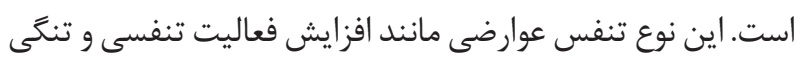
نفس در افرادى با شرايط حاد، به همراه دارد (1) (1).

r. تنفس سكَمنتال (Segmental breathing) در اين روش، بيمار راحت نشسته، فيزيوترايِيست يا مراقب دست خود را در دو طرف قفسه سينه در لوبهاى مختلف رئه ريه بيمار رئن

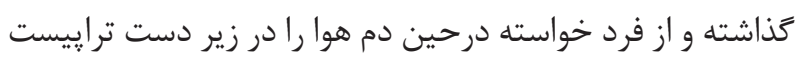
هدايت كند طورى كه حركت دست درمانكر ديده شود و ديخر

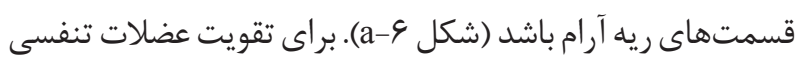

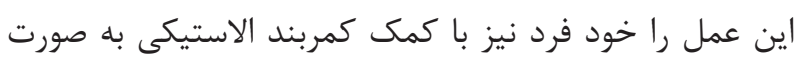
مقاومتى مى تواند انجام دهد. (شكل ع-4) (1) (1). r- دهان خود را ببنديد و از راه بينى هوا را به صورت يك دم عميق وارد ريههاى خود كنيد. ب- در حالى كه لبهاى خود را به حالت غنجهاى (حالت سوت ردون

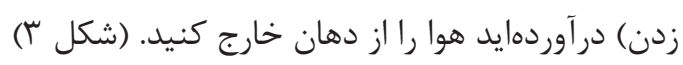

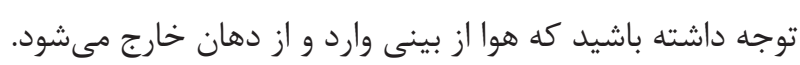

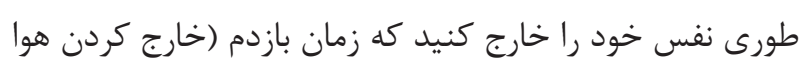

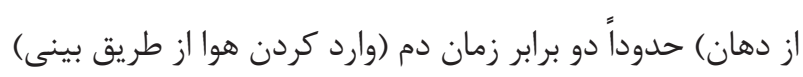

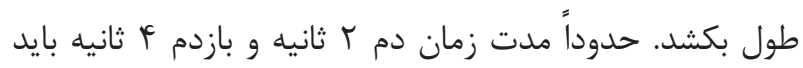

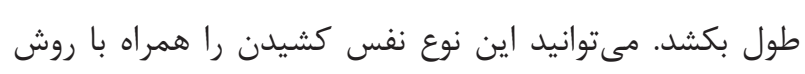

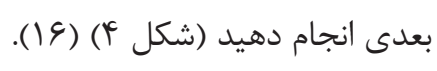

r. تنفس ديافر آماتيك (Diaphragmatic breathing)

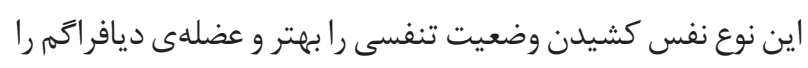

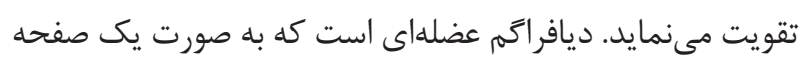

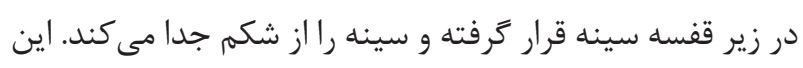
عضله در نفس كشيدن نقش مهمى دارد. جهت انجام تنفس ديافرامماتيك آموزش هاى زير بايد داده شود:

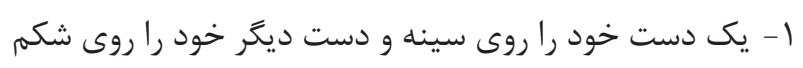
قرار دهيد. r- طورى نفس بكشيد (دم يا وارد كردن هوا در ريهها) كه دست

$$
\text { روى شكم به طرف جلو كشيده شود. }
$$

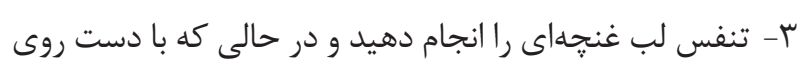

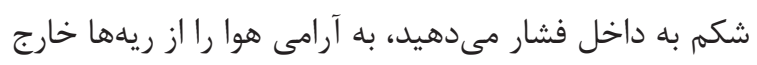
كنيد. توجه كنيد كه دست بايد روى سينه در همان حالت

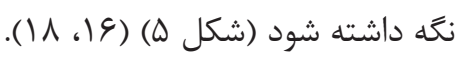
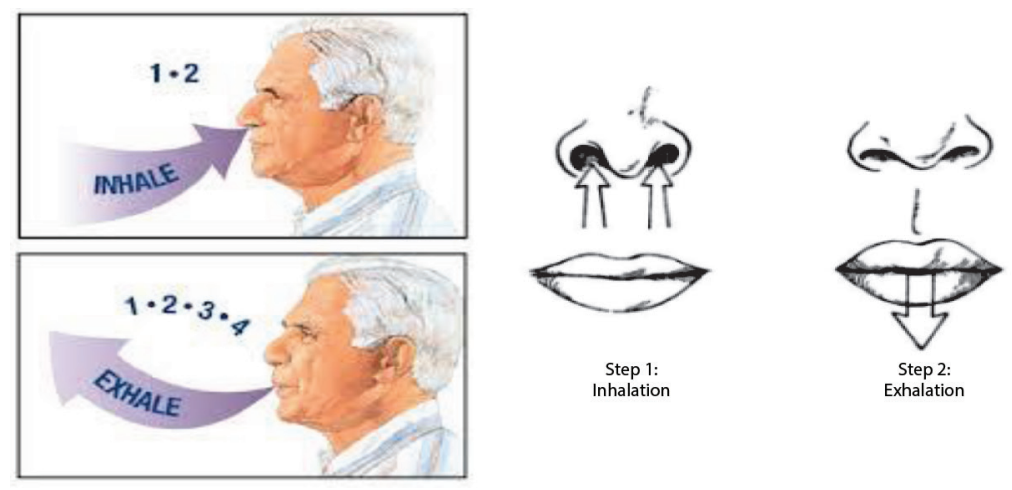

شكل F - روش انجام تنفس لب غنجهاى 


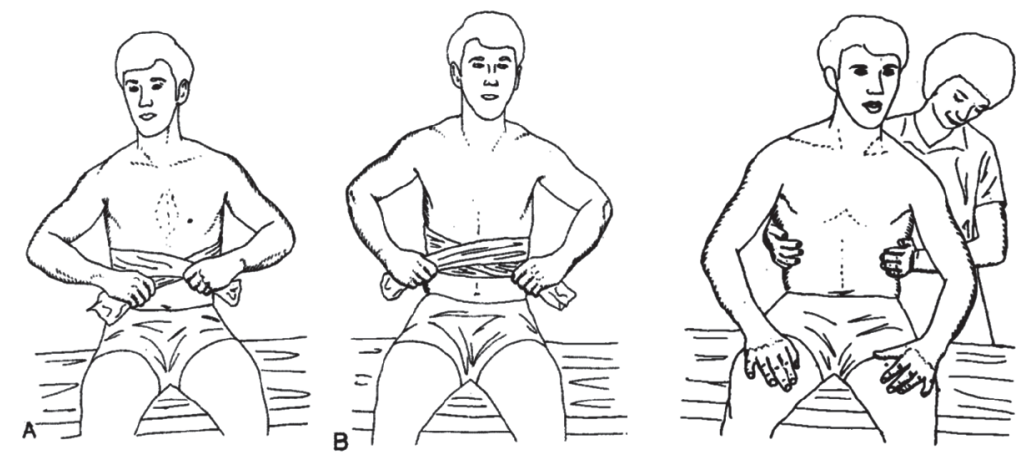

شكل 9- روش انجام تنفس سگمنتال - a ) با كمك تراييست، b) با كمك كمر بند مقاومتى

سمت ريdها مىرود (شكل V) (19، 19).

موارد احتياط

در صورت نارسايى حاد تنفسى كه نشانده كاهش توان ريوى است، افزايش فعاليت تنفسى و تغيير اكسيزن رسانى خون منجر به الگُى تنفسى سريع و كم عمق مىشود. اين الكوى تنفسى كه به صورت خود به خودى توسط فرد اتخاذ مىشود بيانغر يك ليع استراتزى براى به حداقل رساندن تلاش دمى و حداكثر كارايى مكانيكى تنفسى است بنابراين قدرت عضلات تنفسى نيز كاهش مىبايد؛ بنابراين در اين شرايط درمانهاو يروسيجرهاى فيزيوترايى نبايد باعث افزايش بار اضافى تنفسى شود، جرا كه بيمار را مستعد خطر ديسترس تنفسى مى كند. يِيشنهاد شده است كه در بيماران

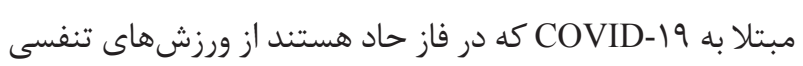

تا زمان گايدار شدن وضعيت بيمار يرهيز كنند (ه).

\section{بحث و نتيجه}

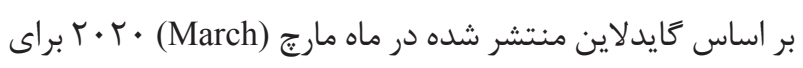

f. تنفس زبانى حلقى (Glossopharyngeal breathing) اين روش شامل انجام عمل دم بدون كمك عضلات كمكى و يا عضلات اصلى تنفسى است. اين نوع تنفس بيشتر براى بيمارانى

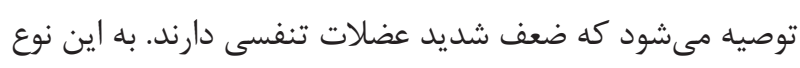
تنفس، تنفس قورباغهاى هم كَته مىشود. در اين روش از بيمار خواسته مىشود جند جرعه از هوا رو با دهان بخيرد، سيس دهان را بسته و هوا را با زبان به سمت حلق و ريه هل دهد. هر جرعه از

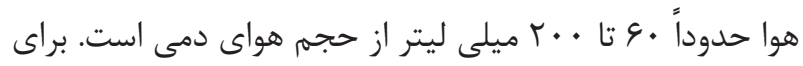

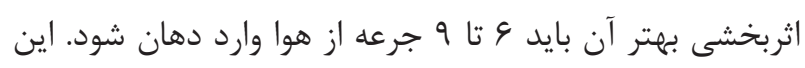
تكنيك باعث افزايش عمق دمى و ظرفيت حياتى مىشود. اين نوع تنفس بيشتر در غواصان استفاده مىشود تا حجم اكسيرن ذخيره را افزايش دهند. (شكل V) (ع)، 9 (1). اين نوع تنفس شامل سه مرحله است: 1 - دهان باز و هوا به داخل حلق و دهان برده مىشود ץ- دهان به كمك زبان بسته مىشود و عضلات حلق هواى بلعيده شده را به سمت اييخلوت باز هدايت مى كند. ז- ايى حلوت بسته مىشود تا مطمئن شود هواى وارد شده به
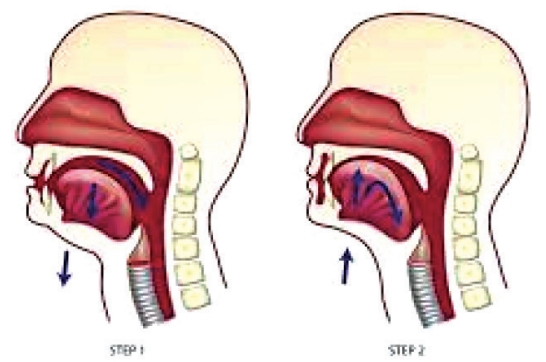

$\pi \mid F^{2}$.

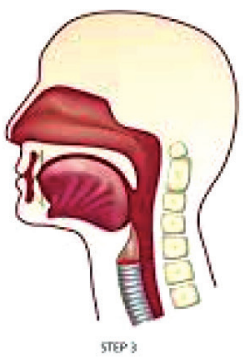

شكل V- تنفس زبانى حلقى

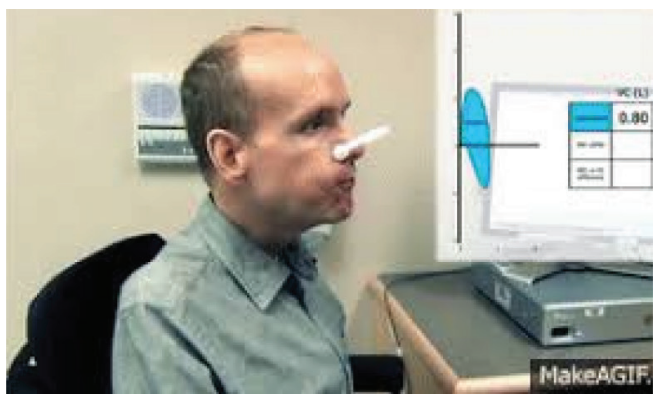

MakeAGIF 


$$
\begin{aligned}
& \text { مخاطبين، ازجمله فيزيوتراييستها، يرستاران و مراقبين بيماران }
\end{aligned}
$$

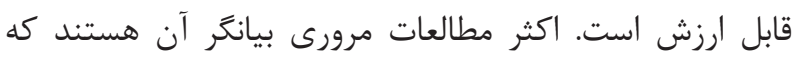

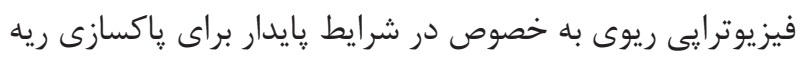

$$
\begin{aligned}
& \text { و بهبود عملكرد تنفسى بيمار يك مداخله ايمن و كارآمد است. }
\end{aligned}
$$

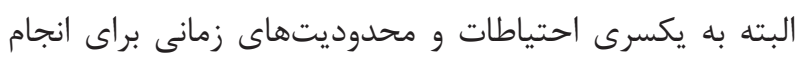

$$
\begin{aligned}
& \text { اين تكنيكها اشاره شده است كه بايد مدنظر قرار كرفته شود. }
\end{aligned}
$$

\section{References}

1- Boseley S. Coronavirus symptoms: What are they and should I call the doctor? 2020.

2- Khani H, Tabarraei A, Moradi A. Survey of Coronaviruses Infection among Patients with Flu-like Symptoms in the Golestan Province, Iran. Med Lab J. 2018;12(6):1-4. HYPERLINK “http:// dx.doi.org/10.29252/mlj.12.6.1" DOI: 10.29252/mlj.12.6.1

3- WHO. Clinical management of severe acute respiratory infection (SARI) when COVID-19 disease is suspected: interim guidance 2020 [cited 202013 March ]. Available from: https://www.who. int/publications-detail/clinical-management-of-severe-acuterespiratory-infection-when-novel-coronavirus-(ncov)-infectionis-suspected.

4- Thomas P, Baldwin C, Bissett B, Boden I, Gosselink R, Granger $\mathrm{CL}$, et al. Physiotherapy management for COVID-19 in the acute hospital setting: clinical practice recommendations. J Physiother. 2020. HYPERLINK "http://dx.doi.org/10.1016/j. jphys.2020.03.011” DOI: $\quad 10.1016 /$ j.jphys.2020.03.011 HYPERLINK “file:///C:IUsers\B.FeizilDownloads\www.ncbi. nlm.nih.gov/pubmed 32312646"PMID: 32312646

5- Lazzeri M, Lanza A, Bellini R, Bellofiore A, Cecchetto S, Colombo A, et al. Respiratory physiotherapy in patients with COVID-19 infection in acute setting: a Position Paper of the Italian Association of Respiratory Physiotherapists (ARIR). Monaldi Archives for Chest Disease. 2020;90(1). HYPERLINK “http://dx.doi.org/10.4081/monaldi.2020.1285" DOI: 10.4081/ monaldi.2020.1285

6- Berney S, Haines K, Denehy L. Physiotherapy in critical care in australia. Cardiopulm Phys Ther J. 2012;23(1):19-25. HYPERLINK “file:///C:IUsers\B.FeizilDownloads|www.ncbi. nlm.nih.gov/pubmed 22807651"PMID: 22807651

7- Behzadinezhad S, Afrasiabifar A, Najafi Doulatabad S, Mousavizadeh A. The Combined effect of Chest Physiotherapy and Respiratory Exercises on Activities of Daily Living on The Patients With Chronic Obstructive Pulmonary Disease. Armaghane danesh. 2018;23(3):267-79.

8- He M, Yu S, Wang L, Lv H, Qiu Z. Efficiency and safety of pulmonary rehabilitation in acute exacerbation of chronic obstructive pulmonary disease. Med Sci Monit. 2015;21:806-12. HYPERLINK “http://dx.doi.org/10.12659/MSM.892769” DOI:

$$
\begin{aligned}
& \text { فيزيوتراييستها در درمان بيماران بسترى مبتلا به } 19
\end{aligned}
$$

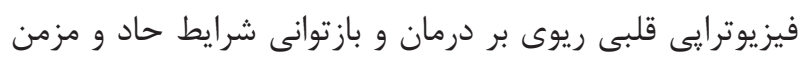

$$
\begin{aligned}
& \text { تنفسى بيماران متمركز است و هدف بهبود توان جسمانى افراد }
\end{aligned}
$$

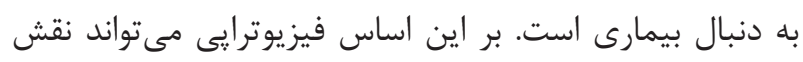

$$
\begin{aligned}
& \text { مؤثرى در درمانهاى تنفسى و توانبخشى جسمانى بيماران مبتلا }
\end{aligned}
$$

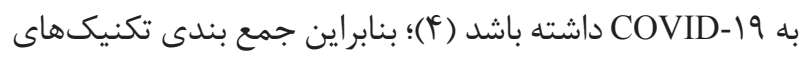

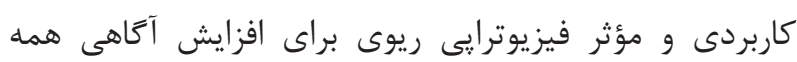

10.12659/MSM.892769 HYPERLINK “file://C:IUsers\B.Feizi Downloads \www.ncbi.nlm.nih.gov\pubmed $\backslash 25783889$ ”PMID: 25783889

9- Kilic L, Pehlivan E, Balci A, Bakan ND. Effect of 8-week Pulmonary Rehabilitation Program on Dyspnea and Functional Capacity of Patients on Waiting List for Lung Transplantation. Turk Thorac J. 2020;21(2):110-5. HYPERLINK "http:// dx.doi.org/10.5152/TurkThoracJ.2019.18202" DOI: 10.5152/ TurkThoracJ.2019.18202 HYPERLINK "file://C:IUsers|B.Feizi Downloads \www.ncbi.nlm.nih.gov\pubmed 32203001 "PMID: 32203001

10- Yang M, Yan Y, Yin X, Wang BY, Wu T, Liu GJ, et al. Chest physiotherapy for pneumonia in adults. Cochrane Database of Systematic Reviews. 2013. HYPERLINK "http://dx.doi.org/10.1002/14651858.CD006338.pub3" DOI: 10.1002/14651858.CD006338.pub3

11- Warnock L, Gates A. Chest physiotherapy compared to no chest physiotherapy for cystic fibrosis. Cochrane Database Syst Rev. 2015(12):CD001401. HYPERLINK "http://dx.doi.org/10.1002/14651858.CD001401.pub3" DOI: 10.1002/14651858.CD001401.pub3 HYPERLINK

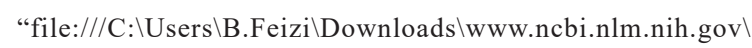
pubmed 26688006"PMID: 26688006

12- Hough A. Physiotherapy in respiratory care: An evidence-based approach to respiratory and cardiac management. Nelson Thornes. 2001.

13- Leelarungrayub J, Eungpinichpong W, Klaphajone J, Prasannarong M, Boontha K. Effects of manual percussion during postural drainage on lung volumes and metabolic status in healthy subjects. J Bodyw Mov Ther. 2016;20(2):356-63. HYPERLINK "http://dx.doi.org/10.1016/j.jbmt.2015.11.002" DOI: 10.1016/j. jbmt.2015.11.002 HYPERLINK “file://C:IUsers\B.Feizi Downloads\www.ncbi.nlm.nih.gov\pubmed 27210854 "PMID: 27210854

14- Paulus F, Binnekade JM, Vroom MB, Schultz MJ. Benefits and risks of manual hyperinflation in intubated and mechanically ventilated intensive care unit patients: a systematic review. Crit Care. 2012;16(4):R145. HYPERLINK "http://dx.doi. org/10.1186/cc11457” DOI: 10.1186/cc11457 HYPERLINK 
"file://C: $\backslash$ Users $\backslash$ B.Feizi $\backslash$ Downloads $\backslash$ www.ncbi.nlm.nih.gov $\backslash$ pubmed 22863373 'PMID: 22863373

15- de Godoy VC, Zanetti NM, Johnston C. Manual hyperinflation in airway clearance in pediatric patients: a systematic review. Rev Bras Ter Intensiva. 2013;25(3):258-62. HYPERLINK "http:// dx.doi.org/10.5935/0103-507X.20130043” DOI: 10.5935/0103507X.20130043 HYPERLINK “file:///C:\Users \B.Feizi $\backslash$ Downloads\www.ncbi.nlm.nih.gov \pubmed 24213091 "PMID: 24213091
16- Solomen S, Aaron P. Breathing techniques- A review. International Journal of Physical Education, Sports and Health. 2015;2(2):23741.

17- Vatwani A. Pursed Lip Breathing Exercise to Reduce Shortness of Breath. Arch Phys Med Rehabil. 2019;100(1):189-90. HYPERLINK “http://dx.doi.org/10.1016/j.apmr.2018.05.005" DOI: 10.1016/j.apmr.2018.05.005 HYPERLINK “file:///C:\ Users $\backslash$ B.Feiz 